\title{
DOCUMENTOS PARA VER, DOCUMENTOS PARA LEER
}

\section{CARLOS SÁEZ \\ Universidad de Alcalá}

1. Es sabido que en las sociedades alfabetizadas pretéritas el uso centralizado de la escritura por parte del estado fue necesario para consolidar su poder y afianzar los procesos para mantener el control sobre sus territorios ${ }^{\prime}$. El documento es en ellas el elemento que contribuye a aportar una estabilidad institucional, pues puede viajar y llegar a casi todos los rincones, a diferencia de otros escritos, como las escrituras expuestas que, aunque más aparatosas, llamativas y dispuestas a la vista de cualquier viandante, permanecen fijas en lugares concretos por los que hay que pasar para recibir su mensaje y percibir su influencia.

La conservación de los documentos es, por tanto, imprescindible para el mantenimiento del poder de papas, reyes, emperadores y demás autoridades públicas del medievo. Esta es una de las razones más poderosas que indujeron la creación y el mantenimiento de archivos. La comunicación escrita por medio del documento se convirtió así en uno de los principales medios de control para consolidar el estado público.

Pero esto mismo puede decirse también de autoridades menores y de personas singulares y privadas. Eclesiásticos, nobles, comerciantes, mercaderes, artesanos y otros individuos guardaron sus documentos para

\footnotetext{
'Este tema fue tratado por Miguel RodRiguez LLOPIS, La escritura y el poder. La emisión de documentos en la sociedad murciana bajomedieval, "Áreas. Revista de Ciencias Sociales» 9 (1988) pp. 9-24

"Anuario de listudios Medievales". 29 (1999)
} 
garantizar sus derechos y propiedades, en especial desde la restauración del derecho romano.

Por tanto, en la Edad Media todo aquel que tiene algo que preservar, mantener o proteger, produce documentos como vía idónea para cumplir tales objetivos. Todos estos escribientes deben ser entendidos como grupos privilegiados que emplean el documento como medio de expresión y comunicación y como un vehículo transmisor y consolidador de sus privilegios, de su ideología e incluso de su propia imagen.

Los documentos contienen actos jurídicos que influyen de forma directa en la política, economía y sociedad. Son objetos escritos que tienen un valor inmediato y duradero. Por ello muchos adoptaron características externas especiales que sus autores les dieron a propósito. Nos referimos a los documentos más solemnes, aquellos que contrastan con otros más sencillos y menos aparatosos en su aspecto, procedentes de los mismos poderes públicos o de autoridades de menor rango, de notarios o de particulares.

En las comunidades alfabetizadas, el poder constituido produce así testimonios gráficos destinados a dirigir mensajes a los súbditos, a propagar su propia imagen y a perpetuar su memoria. Estos testimonios tienen siempre caracteres externos de especial solemnidad y se elaboran con particular cuidado. Estos rasgos tienden a conferir a los testimonios escritos la capacidad de transmitir mensajes relacionados con el poder que los produce, incluso por la simple vía visual. Para alcanzar los fines enumerados, los documentos solemnes son elaborados por técnicos especializados cuya función es garantizar su autenticidad y funcionalidad a través de la utilización de determinadas normas y de la repetición de modelos preestablecidos $^{2}$.

Sin embargo, en la inmensa mayoría de los casos, las oficinas productoras de documentos carecieron de normas cancillerescas fijas, lo que produjo, por un lado, modificaciones constantes en el formulario y aspecto de los documentos y, por otro, la producción de abundantes falsificaciones, fenómeno común a todos los estados medievales europeos que a la larga supuso el origen de la crítica documental moderna.

\footnotetext{
'La elaboración de las piezas solemnes fue descrita por Armando Petrucci, Potere, Spazi urbani, scritture esposte: proposte ed esempi. en Culture et idéologie dans la genèse de l'État Moderne. École Française de Rome, 1985, pp. 85-87.
} 
Hay documentos solemnes que destacan especialmente por su llamativo aspecto externo: las grandes bulas pontificias, los diplomas reales e imperiales germánicos y los privilegios rodados hispanos. A ellos dedicaremos las siguientes páginas.

2. Al describir el diploma solemne de las autoridades públicas europeas occidentales es necesario prestar atención a cuatro elementos, aquellos que lo convierten en símbolo del poder público y en elemento destinado a propagar la imagen y a perpetuar la memoria de sus autores.

En primer lugar, su escritura, que se diferencia de manera ostensible de la empleada en libros y en textos corrientes, tanto en sus proporciones como en los elementos de adorno que las caracterizan, que les confieren una imagen ostentosa y de probada antigüedad. Además, en los diplomas más solemnes es habitual encontrar no uno sino varios tipos diferentes de escritura.

En segundo lugar, la superficie del diploma, que adopta una función anunciadora por medio del añadido de signos gráficos, signaturas y sellos que acompañan al texto, que acentúan con su distribución y aspecto la singularidad del acto jurídico que contiene el documento.

En tercer lugar, es sabido que los diplomas no tienen una superficie escrituraria lisa y homogénea, sino que ésta se ordena en zonas jerárquicas en las que se reparten de manera equilibrada el peso de escritura, por un lado, y el de los símbolos gráficos, por otro. Este layout particular provoca que el punto de mira de quienes ven una pieza recaiga antes en las autoridades que la han producido, representadas por ostentosos signos, que en el contenido jurídico y textual de la misma.

Por último, los diplomas emplean formatos que se desvían de manera ostensible de las formas librarias. El porqué se producen textos diplomáticos de proporciones peculiares, diferentes de las de otros escritos, es una cuestión no casual que debe ser explicada y que caracteriza a los diplomas solemnes ${ }^{3}$.

Poca atención han recibido hasta ahora los elementos enumerados por parte de los especialistas. Desde el siglo XVIII han tenido incluso más

\footnotetext{
${ }^{3}$ Esta metodología fue expuesta por Peter Rück, Die Urkunde als Kunstwerk, en Kaiserin Theophanu. Begegnung des Ostens und Westens um die Wende des ersten Jahrtausend. Gedenkschrift des Kölner Schnütgen-Museums zum 1000. Todesjahr der Kaiserin. ed. por Anton von Euw y Peter SCHREINER, Köln 1991, pp. 311-333.
} 
rechazo que aceptación, después de ser abordados por primera vez por el alemán Gatterer en $1765^{4}$, por lo que no vendrá mal abordar su aplicación dentro del mundo documental hispánico.

3. Pero para ilustrar la teoría veamos en primer lugar dos ejemplos no hispanos: un diploma real alemán y una bula papal.

El primero (lámina 1), de Enrique IV de Alemania y datado en $1067^{5}$, tiene aspecto de un verdadero póster o cartel anunciador. Su primera línea, confeccionada a base de letras alargadas (elongata), está confeccionada para llamar la atención mientras que la segunda y sucesivas están destinadas a ser leídas. Nuevas elongata aparecen en la suscripción real dispuesta a ambos lados del signo monogramático. El cuerpo principal del texto se escribe en escritura diferente en la que las letras bajas son de pequeño módulo mientras que las altas presentan astiles muy altos y adornados en su extremo superior con artificiosos lazos. La línea de datación se escribe en otra escritura diferente, menos solemne, lo que completa la variedad de escrituras típica de estos diplomas. Además, a aumentar la solemnidad contribuyen la gran separación existente entre líneas y la amplia porción de la superficie escrituraria que no ha recibido escritura y se encuentra vacía.

Zona de texto y zona de autentificación se reparten el espacio gráfico de manera equitativa, ocupando la segunda la parte inferior. Esta disposición, atractiva al ojo humano, convierte el diploma en un verdadero cartel anunciador en el que el monograma real, el sello, que se halla fragmentado, y las elongata son los elementos que antes atraen la atención del posible lector.

El diploma tiene además un formato alargado en el que existe una simetría perfecta entre las dos zonas aludidas, aunque ello no sea regla usual en los documentos reales germánicos.

El segundo documento (lámina 2) es una bula de Alejandro III fechada en $1178^{6}$. Se trata de un ejemplo ya canonizado de la bula papal

${ }^{4} J . C$. GATTERER, Elementa artis diplomaticae universalis, Göttingen 1765, obra en la que dedica abundantes páginas a la semiótica de las fuentes diplomáticas; de Rück, pp. 311-312. a quien hay que considerar el verdadero rescatador de esta materia para la historiografía actual.

${ }^{5}$ Dirigido a Kaiserswerth; original en HStA Düsseldorf, foto del Lichtbildarchiv (archivo de diapositivas; = LBA) de la Universidad de Marburg, $\mathrm{n}^{\circ}$ 8816; reproducido en RÜCK, $o b$. cit., p. 317, Abb.4, y comentado en pp. 331 y 333.

${ }^{6}$ Dirigida a St. Ursanne; original AAEB Porrentruy; foto del LBA de Marburg, $n^{\circ} 12137$; reproducida en RÜCK, $o b$. cit, p. 329, Abb. 8 y comentada en pp. 320-321 y 330-331. 
elaborada a mediados del siglo XI, que se constituirá en modelo a imitar por todo occidente y que a la vez sufrirá influencia del diploma solemne real e imperial germánico.

En la escritura del documento, cuyas palabras se condensan como consecuencia del paso de la escritura carolina a la gótica, encontramos de nuevo varios tipos de letra: elongata en la primera línea y en la datación, nombre de Inocencio en elongata menos pronunciadas, escritura del bloque de texto, suscripción papal, autógrafos de los suscriptores y línea de cancillería.

La superficie escrituraria muestra también dos zonas, texto y validación, que no guardan simetría en este caso, pues el bloque del texto se sitúa en la parte superior del pergamino, disposición que resulta más atractiva al ojo humano.

En la zona de validación, los signos papales polarizan la atracción del lector y evocan el poder de la Iglesia. Se divide ésta en cuatro bloques de diferente peso: los signos gráficos (rota y Bene Valete monogramático) con la suscripción papal, las suscripciones autógrafas de los cardenales (dispuestas en dos columnas y acompañadas de cruces invocativas y abreviaturas de la palabra subscripsi), la línea de datación y, por último, la plica con su sello, que ya se ha independizado de la superficie escrituraria. En todo este entramado, los signos gráficos se manifiestan como los elementos más llamativos y se convierten en el centro de la atención de quienes observan el diploma.

4. ¿Cómo se comporta el diploma solemne de los reinos noroccidentales hispanos? A falta de un estudio completo, que constituiría un trabajo inabordable aquí ${ }^{7}$, haremos un breve recorrido por algunos eslabones dispuestos por orden cronológico.

El primer documento real original que conservamos, el renombrado diploma del rey Silo del año 775 , no resulta un ejemplo perfecto para

\footnotetext{
${ }^{7} \mathrm{Y}$ que de hecho constituye una tesis doctoral que se elabora bajo mi dirección, cuyo autor es Rogelio Pacheco Sampedro, Colaborador Honorífico de la Universidad de Alcalá.
} 
nuestros fines, pues parece que se trata más bien un documento privado emitido por una persona pública que un documento de tal condición ${ }^{8}$.

La falta de titulación regia que se observa en el diploma es un elemento a tener en cuenta, pero no parece un argumento del todo determinante para considerar el diploma como privado, pues hay preceptos reales de los primeros tiempos en los que se observa la misma circunstancia ${ }^{9}$. Más significativa es otra circunstancia que aparece en la donación de Silo, en la que puede leerse una fórmula típica de los documentos privados que expresa la trasmisión del dominio que, desde el momento de la entrega del documento, es apartado del derecho del donante y entregado al derecho de los donatarios: «...et omnia de meo iure abrasum et in vestro iure tradito et confirmatum...» Esta fórmula aparece en todas las donaciones privadas pero no en las reales, con excepción de la de Silo ${ }^{10}$.

El aspecto de esta pieza nos muestra un ejemplar muy largo y de escasa altura, con un corte irregular en especial en su parte inferior. La mayor parte de la superficie del pergamino esta ocupada por el cuerpo del texto, redactado en una única y sencilla visigótica cursiva, mientras que las suscripciones se apelmazan en la su parte inferior, a la fuerza dispuestas de manera irregular debido a la necesidad provocada por el poco espacio libre disponible ${ }^{\prime \prime}$. Así pues, hay en el diploma dos zonas (texto y validación) pero mal delimitadas entre sí e irregulares debido a un cálculo defectuoso de la relación 'texto a escribir/superficie escrituraria disponible' por parte del copista. Es sintomático el contraste de este diploma con otro del mismo año

\footnotetext{
${ }^{8}$ La última edición del mismo es de Emilio SÁEZ, Colección Documental del Archivo de la Catedral de León (775-1230), I (775-952), documento 1, pp. 3-5, con reseña de facsímiles, el mejor de los cuales es sin duda el editado en El Diploma del rey Silo, "Textos singulares de la España Medieval» I, colección Joyas bibliográficas, dirigida por Carlos ROMERO DE LECEA. Madrid 1971. Se trata de un documento tan conocido que no estimo necesario incluir aquí su reproducción.

${ }^{9}$ Por ejemplo, en el precepto de Ordoño I, fechado en 28 de junio del 860 , y en el de Alfonso III, de 10 de julio del 875, editados por E. SÁEZ, cit., documentos 2 y 7 , respectivamente.

${ }^{10}$ Concepción MEndo CaRmona, Consideraciones sobre el concepto de documento privado. «SignO. Revista de Historia de la Cultura Escrita» 3 (1996) Universidad de Alcalá, pp. 20-21. Luis G. de VALDEAVELLANO consideraba el documento como privado en La época del rey' astur Silo y el documento del año 775 , en El Feudalismo hispánico y otros estudios de Historia medieval, Barcelona 1981, pp. 193-94. El diploma plantea otros problemas desde el punto de vista semiótico, que se tratan en la tesis doctoral de Rogelio Pacheco, antes mencionada.

"Una de las suscripciones, precisamente la de mayor tamaño, es confirmación posterior de Alfonso II, y al dorso del diploma se encuentran otras suscripciones reales también posteriores.
} 
emitido por Carlomagno ${ }^{12}$, que cuenta con una perfecta estructura, gran distancia interlineal, mucho espacio en blanco, perfecta disposición de los elementos de validación y una escritura elegante, pretenciosa y artificiosa.

5. Aspecto parecido, aunque algo más ordenado, tiene el siguiente ejemplo que hemos escogido (lámina 3). Se trata de un diploma de Alfonso $\mathrm{V}$ de León, fechado el 19 de septiembre del 1012 ${ }^{13}$. Al crismón de tradición visigótica ${ }^{14}$ sigue una primera línea que en sus inicios insinúa unas tímidas elongata poco pronunciadas, que hacia el final de la línea han adaptado ya el módulo habitual de la escritura del resto del documento. Tampoco aparecen aquí, pues, diferentes tipos de letra en el texto, redactado por el célebre Sampiro, copista a la vez de diplomas y de libros, que suscribe con su característico monograma formado por letras, elementos gráficos y escritura cifrada ${ }^{15}$.

Junto a este elemento resaltan en el diploma los demás signos de validación, muchos de ellos trazados de manera tan tosca que inducen a considerarlos autógrafos, pues Sampiro en ningún caso los hubiera dibujado $\tan \mathrm{mal}^{16}$. La superficie escrituraria se ha dividido claramente en dos zonas, que mantienen un equilibrio perfecto confirmando así la aptitud gráfica reconocida al copista. En la superior, siguiendo las reglas de visibilidad del ojo humano, se sitúa el texto, y en la inferior la zona de validación en la que la suscripción real, tres columnas de confirmaciones no autógrafas, como es habitual, y, sobre todo, los signos aludidos, forman el polo de atracción principal del diploma.

\footnotetext{
${ }^{12}$ Facsímil en Rück, ob. cit., p. 313.

${ }^{13}$ Ed. J. Manuel Ruiz ASENCIO, Colección Documental del Archivo de la Catedral de León, III, (986-1031), n 707, pp. 263-265. Original de la Catedral de León $\mathrm{n}^{\circ} 990$.

${ }^{14}$ Sobre el que recientemente se propugnan interpretaciones diversas que relacionan este signo con más bien con una actuación notarial que se plasmaría por medio de la representación esquemática de la palabra lectus (que podría ser también legimus). Véase Concepción MENDO CARMONA, La suscripción altomedieval, "Signo», 4 (1997) pp. 207-230 y Luis CASADO DE OTAOLA, Per visibilia ad invisibilia: Representaciones figurativas en documentos altomedievales como símbolos de validación y autoría, «Ibídem» p. 43.

${ }^{15}$ En la monografía clásica de este personaje se estudian sus costumbres escriturarias: Fray Justo PÉREZ DE URBEL, Sampiro, su crónica y la monarquía leonesa en el siglo $X$, CSIC, Madrid 1952.

${ }^{16} \mathrm{~A}$ pesar de que, en la zona de la Península de la que nos ocupamos, todavía está por estudiar con profundidad el tema de las suscripciones autógrafas, que se muestran ser raras en extremo.
} 
Una última suscripción aparece aislada a la derecha del diploma, dispuesta de abajo hacia arriba, orientación que habitualmente se reserva al copista, que aquí ha aparece en una columna de confirmantes.

El formato de esta pieza sigue la tradición anterior y ha sido modelado con forma alargada. Una rotura en la zona superior izquierda es síntoma de falta de solemnidad en su confección. Este hecho no sucedería nunca en una bula solemne o en un documento real o imperial alemán, y permite sospechar que se ha aprovechado un pedazo de pergamino defectuoso.

Pero no todos los diplomas de la época tenían este aspecto. No nos es posible profundizar en esta cuestión, por razones ya expuestas, pero hay ejemplares que presentan formatos diferentes, desde casi cuadrados a otros alargados en extremo. Asimismo, es posible descubrir variaciones en otros elementos, como puede apreciarse, por lo que se refiere a la escritura, en un diploma reproducido por García Villada ${ }^{17}$, o, en lo referente a la manera de disposición de los elementos escriturarios en la superficie del pergamino, en alguno de los diplomas que expedirá más adelante doña Urraca según la costumbre aragonesa.

6. Una etapa intermedia hacia los privilegios rodados está constituida por la época en que el documento solemne castellano-leonés se plasma en los privilegios signados, que se usan hasta la muerte de Alfonso VII. En la lámina 4 puede verse uno de ellos emitido por Sancho II $^{18}$. Su estructura es similar a la de los diplomas anteriores, con una zona de texto - muy amplia - y una de validación en la parte inferior del pergamino, en la que se disponen, por este orden, una columna de confirmantes, el signo real, otra columna de confirmantes y una tercera de testigos y, al final, la suscripción del copista. Sin profundizar en exceso en su descripción semiótica notamos a primera vista una cuestión esencial que ha modificado el aspecto de la superficie escrituraria: han desaparecido todos los signos de testigos o confirmantes y el del copista, que hacían sombra al signo real, el cual los desplaza y adopta un tamaño que anuncia ya la fuerza de atracción visual que

\footnotetext{
${ }^{17}$ Zacarías García Villada, Paleografía española, Madrid 1923, II, nº 53.

${ }^{18} 1067$, diciembre 11. Sancho II a Oña. Archivo Histórico Nacional, Clero, Pergaminos, 270/20. La pieza es considerada copia por Manuel LUCAS ÁlVAREZ, Cancillerías reales asturleonesas (718-1072), León 1995, p. 375, regesto R1-447; sin embargo, aquí interesa más su aspecto que la discusión sobre su posible originalidad.
} 
tendrá este elemento en los privilegios rodados. Además, el signo de Sancho II adopta aquí una forma de edificio de inspiración clásica entroncando con la costumbre desarrollada en el imperio germánico de plasmar mediante motivos arquitectónicos los signos del canciller ${ }^{19}$.

Pero los privilegios signados supusieron sólo una corta etapa en los hábitos documentales hispánicos y pronto se llegó a los rodados. En ellos el elemento gráfico esencial es la rota, que substituye a los anteriores signos y se convierte en foco de atracción principal para el ojo humano. La adopción de la rota por los hijos de Alfonso VII ha sido ya objeto de varios estu$\operatorname{dios}^{20}$, pero no así su uso fuera del ámbito del documento público, que es frecuente en Galicia ${ }^{21}$.

7. El privilegio rodado supone la culminación del proceso de búsqueda de un arquetipo documental que cumpla con los objetivos propagandísticos que se proponen sus emisores para convertir la pieza documental en una prolongación de su autor. Ello se logra dotando al documento de un aspecto característico y de gran solemnidad que lo convierte en un póster cuya procedencia es reconocida por los súbditos, alfabetizados o no, por la simple vía visual. De esta manera, el privilegio rodado se inserta de forma plena en la mutación que se produce en el siglo XII, a partir del cual la cultura comienza a evolucionar de una plena oralidad

\footnotetext{
${ }^{19}$ Véase una relación completa de imágenes en Peter RücK, Bildberichte vom König. Kanzlerzeichen, königliche Monogramme und das Signet der Salischen Dynastie, «elementa diplomatica» 4, Marburg an der Lahn 1996, pp. 72 y siguientes; quizá el más parecido al signo de Sancho II sea la ilustración $n^{\circ} 114$, p. 87, que representa un edificio similar aunque en tres dimensiones.

${ }^{20}$ Tanto clásicos, como el de Anton EITEL, Rota und Rueda, «Archiv für Urkundenforschung» VI (1914) pp. 299-336, como más recientes: José Antonio MARTín FUERTES, El signum regis en el reino de León. Notas sobre su simbolismo, en Graphische Symbole in mittelalterlichen Urkunden. Beiträge zur diplomatischen Semiotik, ed. Peter RüCK, Thorbecke, Sigmaringen 1996, pp. 463-478. En esta misma obra, pp. 407-423, un artículo diserta sobre el origen y significación de la rota papal: Joachim DAHLHAUS, Aufkommen und Bedeutung der Rota in der Papsturkunde. En este campo resulta de sumo interés la descripción del mundo procedente de las Etimologías, en la que San Isidoro parece estar hablando de una rota (cosa que no ha escapado a DAhlhaus). Puede verse la traducción del pasaje en María del Carmen PALLARES MÉNDEZ, Ilduara, una aristócrata del siglo X, Publicacións do Seminario de Estudos Galegos, Santiago de Compostela 1998, p. 18.

${ }^{21}$ De manera un tanto marginal toco este tema en mi trabajo Edición digital y semiótica diplomática: a propósito de un documento de Caaveiro, Homenaje al Prof. Filgueira Valverde. Museo de Pontevedra, todavía en prensa.
} 
hacia un registro más visual ${ }^{22}$. El documento se lee, se escucha pero también se ve y se mira; recuérdese la conocida fórmula introductoria sepan cuantos esta carta vieren e oyeren. La lectura solemne de que debía ser objeto convirtió al privilegio en uno de los primeros espacios reconocidos públicamente para exponer la publicidad del poder ${ }^{23}$.

Es decir, estos documentos además de ser vistos, son reconocidos por su aspecto. Y el elemento esencial para lograr este fin, junto con los enumerados en el anterior párrafo, es el signo rodado, cuyo tamaño y aspecto quita importancia a todos los demás presentes en el documento, inclusive al sello, que, mucho más pequeño, queda relegado a un segundo plano como puede verse en la lámina $5^{24}$. Este signo debió suponer en su época un polo de atracción fortísimo para la vista, pues destaca sobre cualquier otro elemento gráfico. Aun hoy es así. La catedral de Santiago elabora camisetas con motivos ornamentales, procedentes sus códices medievales, y uno de los modelos más representados es un colorido signo rodado. Las prendas que lo portan resultan ser siempre las primeras que se venden y agotan. Y es de suponer que la inmensa mayoría de los compradores desconocen el significado del signo ${ }^{25}$. Por tanto, incluso sin saber de qué se trata, el signo rodado produce todavía hoy una irresistible atracción al espectador. Su elección, diseño y modificación hasta convertirlo en un elemento colorido y decorado supuso, en definitiva, un gran acierto por parte de los cancilleres castellano-leoneses.

\footnotetext{
${ }^{22}$ Antonio CASTILlo GómEZ, Del oído a la vista: espacios y formas de la publicidad del escrito (siglos XV-XVI), en Pensamiento Medieval Hispano. Homenaje a Horacio SantiagoOtero, ed. José María Soto RÁBANOS, CSIC, Madrid 1998, pp. 475-476.

${ }^{23}$ Trata la lectura en voz alta en la Alta Edad Media Roger Wright, La Traducción entre el Latín y el Romance en la Alta Edad Media, «Signo», 6 (1999) en prensa. Para siglos posteriores puede verse el artículo de A. CASTILLO citado en la nota anterior.

${ }^{24} 1243$, septiembre 13. Fernando III a la Orden de Santiago. Archivo Histórico Nacional, Sigilografía, caj. $9 \mathrm{n}^{\circ} 2$. Facsímil en Cuenca y la Orden de Santiago. Exposición conmemorativa de la inauguración de la Casa de la Cultura. Julio de 1965. Cuenca 1965, lámina sin numerar. Es de notar el sello del diploma, que en su anverso presenta un castillo de tres torres y en el reverso el león visible en nuestra reproducción. En la elaboración de la pieza Fernando III sigue la costumbre castellana (es decir, el símbolo del reino de León no se ha incorporado a la rueda) y la unión de Castilla y León sólo trasluce por el sello. Sobre la introducción de este elemento por Alfonso VII es de interés el trabajo de R. FLETCHER, Diplomatic and the Cid revisited, "Journal of Medieval History" 2, 4 (1976) Amsterdam.

${ }^{25}$ Como también lo desconocen las vendedoras de las tiendas de la catedral, a quienes debemos la noticia.
} 
Pero a pesar de su éxito, el privigelio rodado no estará exento de evolución, tema del que no podemos ocuparnos aquí ${ }^{26}$. Nuevos elementos se le irán añadiendo, el formato pasará a ser alargado a imitación de las bulas pontificias, se canoniza la situación de confirmantes en columnas y en lugares fijos, se emplearán diferentes tipos de letra, el signo se complica, se decora y se colorea, y algo parecido sucederá con el crismón inicial y con otros elementos gráficos del diploma. Estas novedades llegarán a convertir a estos privilegios en verdaderas obras de arte miniaturísticas en el siglo XV, buen testimonio de las cuales podrían ser los ejemplares expedidos por Juan I y conservados en el Archivo General de Simancas ${ }^{27}$. Raro es el añadido de motivos artísticos a los privilegios, pero hay una excepción, el célebre diploma de Sancho IV depositado en el Archivo Histórico Nacional, en el que el rey elige sepultura en la catedral de Toledo. Toda la escena, a la que concurren el monarca, sus hijos, el arzobispo y los canónigos de la catedral, junto con un gran botafumeiro de tradición compostelana, queda reflejada en torno a la rueda convirtiendo a este privilegio probablemente en el más solemne de los existentes.

En definitiva, el documento solemne presenta una forma externa llamativa para demostrar un estatus político determinado: sólo a quienes les es dado producir estos documentos les es permitido un despliege semejante de lujo y ostentación. Las pretensiones políticas y propagandísticas del poder público son, por tanto, las que producen un tipo documental de las características descritas.

En conclusión, la función placativa del diploma solemne lo convierte en una verdadera obra de arte, además en una prolongación gráfica de sus autores con el fin de cumplir con la función propagandística que se pretende por medio de su llamativo aspecto. Existen en la sociedad medieval algunos intentos imitativos ${ }^{28} \mathrm{y}$, como contrapunto, otros muchos documentos más

\footnotetext{
${ }^{26}$ Existe una tesis doctoral sobre el tema, de la que se editó un resumen de 47 páginas: María Teresa VILLAR ROMERo, Privilegio y signo rodado, Facultad de Filosofía y Letras, Madrid 1966. En el artículo citado de J. A. MARTín FUERTES se recoge otra bibliografía anterior, testimonio de la atracción que siempre ha tenido este tipo documental para el investigador.

${ }^{27}$ Reproducidos a todo color en Los archivos españoles. Simancas, Ministerio de Cultura, Lunwerg Editores, Barcelona-Madrid 1993, pp. 18-19.

${ }^{28}$ El fenómeno imitativo por parte de las autoridades menores y por particulares es constante en toda la Edad Media. Desde el momento en que un documento público canoniza, comienza a ser imitado. Incluso las ruedas, como queda dicho, siguieron esta suerte. Este proceso imitativo es cada vez es más rápido y prácticamente desaparece con la llegada del mundo
} 
sencillos, menos solemnes y de confección menos vanidosa. Pero su historia es otra bien diferente ${ }^{29}$.

\section{RÉSUMÉ}

L'écriture a eté toujours un élement necessaire pour consolider le pouvoir public dans les societés alfabetisées. C'est pour ca qu'elles produisent des documents de caracteristiques grafiques et aspect speciaux les quels aident à répandre l'image de ses auteurs et a perpétuer leur memoire. Cet fin propagandistique vien acqueri parmi de documents très solemnes, comme les privilèges pontificales et germaniques, ou les "privilegios rodados" de Castille. auxquels cet article est dedié.

\section{SUMMARY}

Wrigting has been a necessary element to consolidate public power in alphabetisised societies. With this purpose they produce some kinds of diploms with a special aspect which contribute to propagate the image of their authors and to perpetuate their memory. This propaganda is achieved whith solemn charters like papal and german privileges or the castilian "privilegios rodados". This paper deals with this last diploms.

moderno, con el que la mayoría de las solemnidades documentales llegan a su fin.

${ }^{29}$ Además de la bibliografía citada hasta aquí, me han resultado de utilidad las siguientes obras: Irmgard FEES, Abbildungsverzeichnis der original überlieferten fränkischen und deutschen Königs- und Kaiserurkunden von den Merowingern bis zu Heinrich VI., "elementa diplomatica" 1 (ed. Peter RüCK), Marburg/Lahn, Institut für Historische Hilfswissenschaften, 1994; Olivier GuYOTJeannin, Jacques PyCKE, Benoît-Michel Tock, Diplomatique Médiévale, 1993; Peter RÜCK, Mabillons Spur, ed. de ---, con 22 artículos, Marburg 1992. 


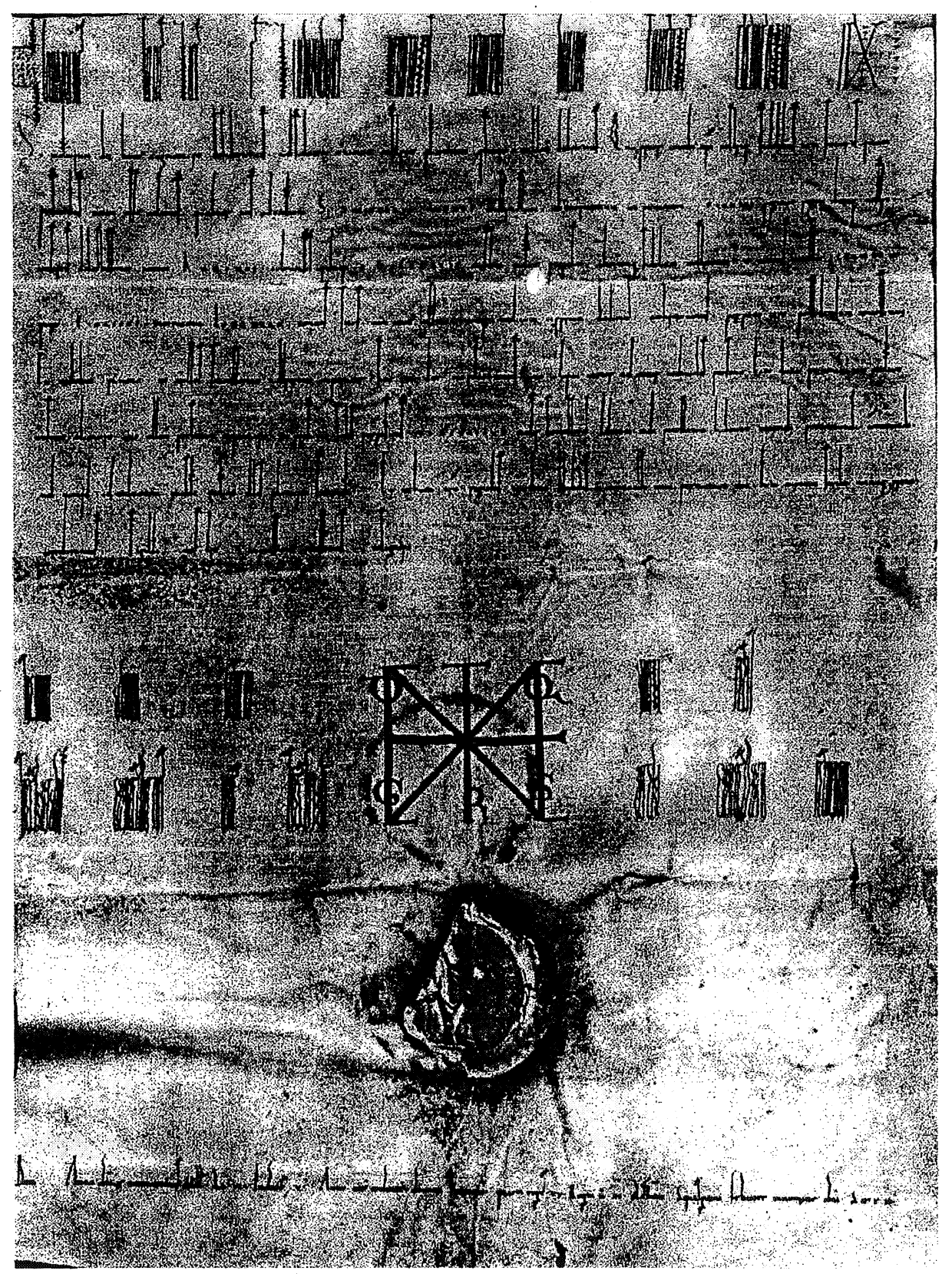

Lámina 1. 


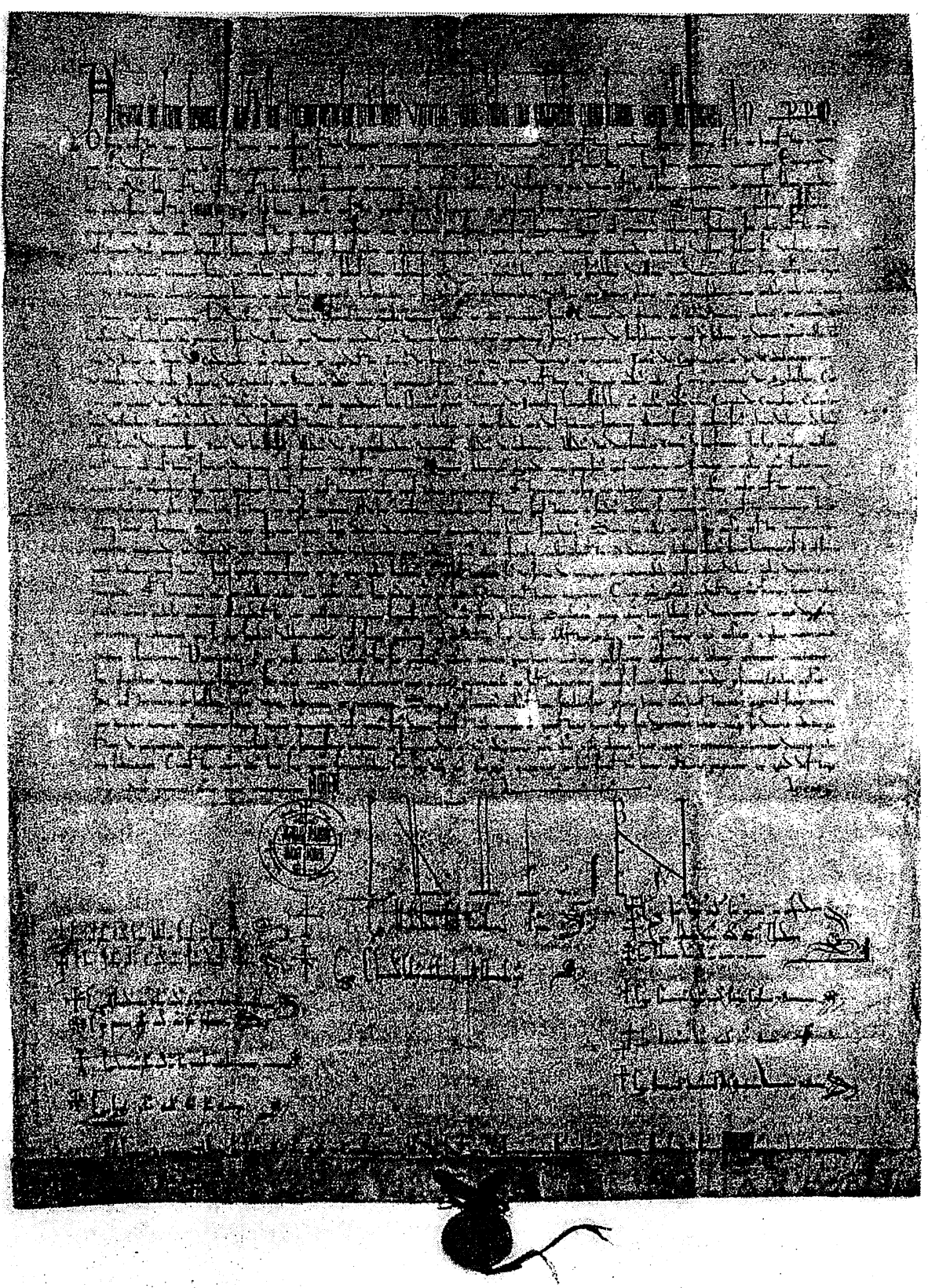

Lámina 2. 


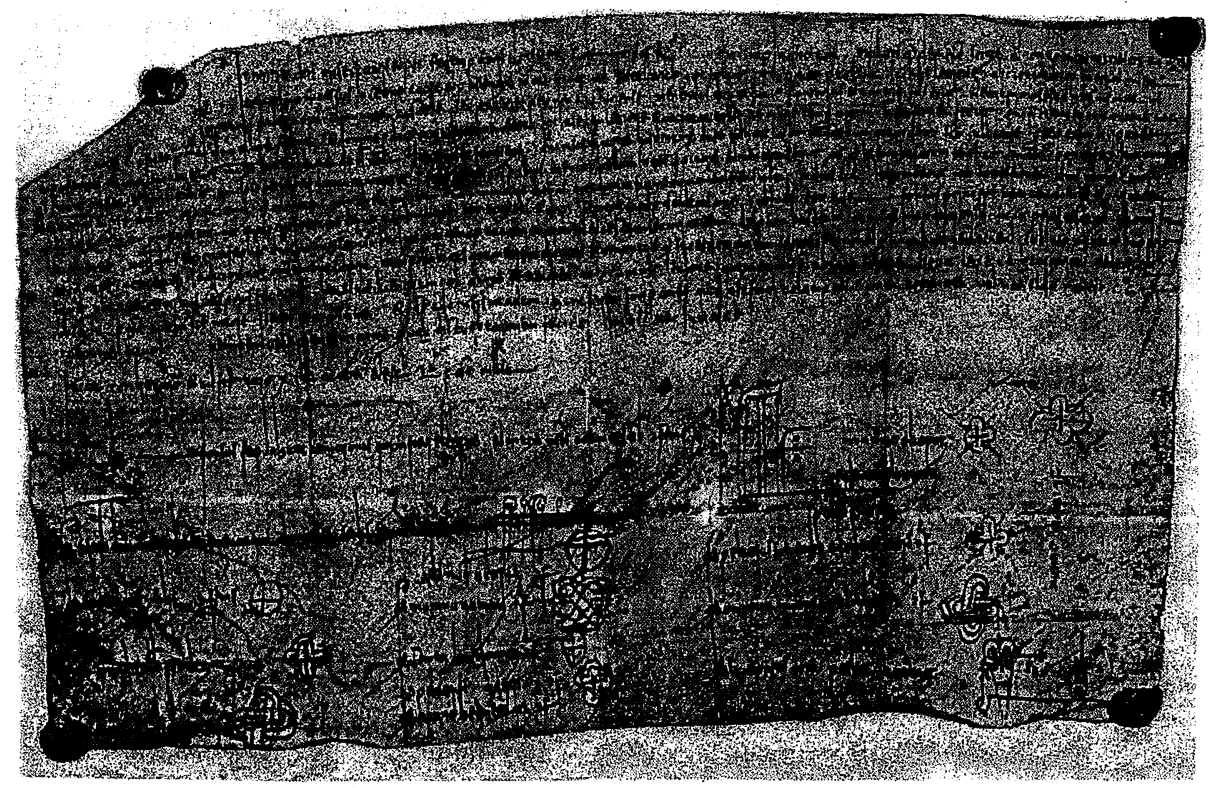

\section{Lámina 3.}




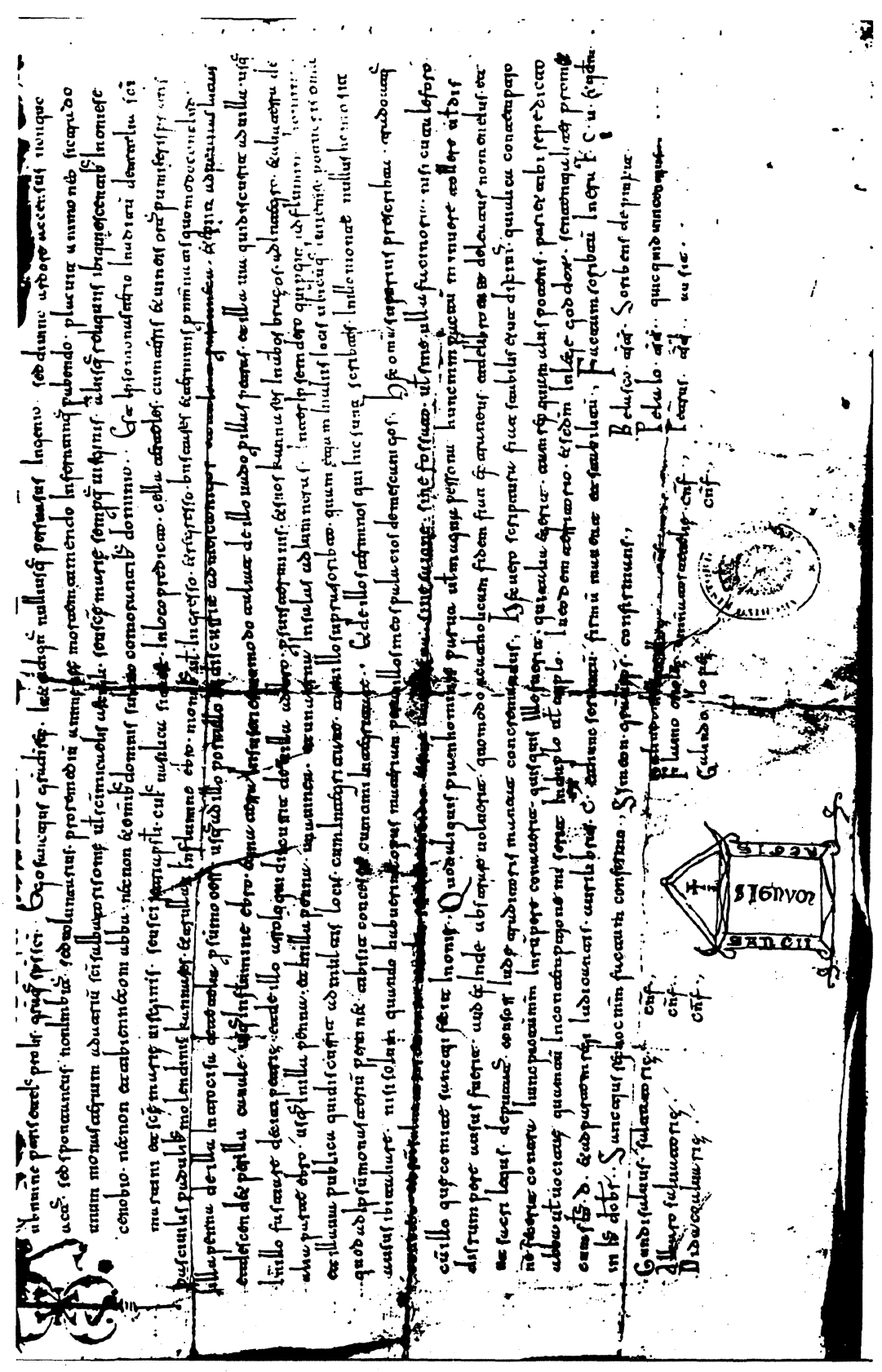

Lámina 4. 


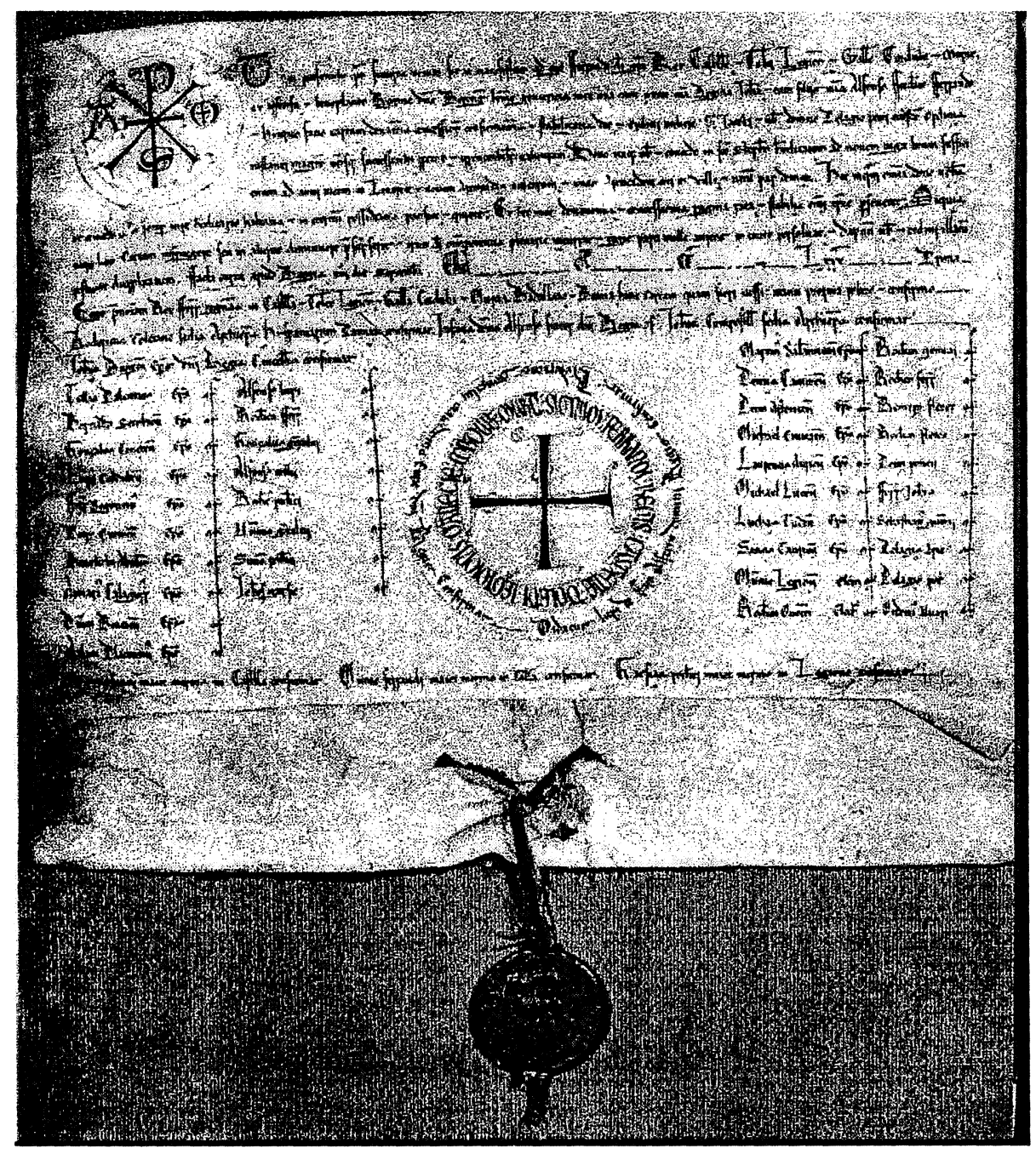

Lámina 5. 